\title{
Dental Education About Patients with Special Needs: A Survey of U.S. and Canadian Dental Schools
}

\author{
Meggan Krause; Lauren Vainio; Samuel Zwetchkenbaum, D.D.S.; \\ Marita R. Inglehart, Dr.phil.habil.
}

Abstract: The objectives of this study were to explore how U.S. and Canadian dental schools educate students about special needs patients and which challenges and intentions for curricular changes they perceive. Data were collected from twenty-two dental schools in the United States and Canada with a web-based survey. While 91 percent of the programs covered this topic in their clinical education, only 64 percent offered a separate course about special needs patients. The clinical education varied widely. Thirty-seven percent of the responding schools had a special clinical area in their school for treating these patients. These areas had between three and twenty-two chairs and were funded and staffed quite differently. Most programs covered the treatment of patients with more prevalent impairments such as Down syndrome ( 91 percent), autism spectrum disorders ( 91 percent), and motion impairments ( 86 percent). Written exams were the most common outcome assessments (91 percent), while objective structured clinical examinations (18 percent) and standardized patient experiences ( 9 percent) were used less frequently. The most commonly reported challenge was curriculum overload ( 55 percent). The majority ( 77 percent) planned educational changes over the next three years, with 36 percent of schools planning to increase clinical and 27 percent extramural experiences. The findings showed that the responding U.S. and Canadian dental schools had a wide range of approaches to educating predoctoral students about treating special needs patients. In order to eliminate oral health disparities and access to care issues for these patients, future research should focus on developing best practices for educational efforts in this context.

\begin{abstract}
Ms. Krause is a dental student at the University of Michigan; Ms. Vainio is a dental student at the University of Michigan; Dr. Zwetchkenbaum is Director of Hospital Dentistry, University of Michigan; and Dr. Inglehart is Associate Professor of Dentistry, Department of Periodontics and Oral Medicine, School of Dentistry, and Adjunct Associate Professor of Psychology, Department of Psychology, College of Literature, Science, and Arts, University of Michigan. Direct correspondence and requests for reprints to Dr. Marita Inglehart, Department of Periodontics and Oral Medicine, School of Dentistry, University of Michigan, 1011 North University Avenue, Ann Arbor, MI 48109-1078; 734-763-8073 phone; 734-763-5503 fax; mri@umich.edu.
\end{abstract}

Keywords: access to care, dental education, dental care for disabled, patients with special needs, oral health care for the underserved

Submitted for publication 3/22/10; accepted 5/26/10

I n September 2008, Dehaitem et al. ${ }^{1}$ published an article in the Journal of Dental Education reporting the findings from a survey of dental hygiene programs in the United States concerning their curricular efforts regarding the treatment of patients with special needs. The Commission on Dental Accreditation (CODA) defines special needs patients as patients "whose medical, physical, psychological, or social situations make it necessary to consider a wide range of assessment and care options in order to provide dental treatment. These individuals include, but are not limited to, people with developmental disabilities, cognitive impairment, complex medical problems, significant physical limitations, and the vulnerable elderly" (p.15). ${ }^{2}$ Dehaitem et al. reported that nearly all U.S. dental hygiene programs (98 per- cent) covered this material in lectures, but that only 42 percent required their students to gain clinical experiences with special needs patients. In addition to analyzing how the dental hygiene programs covered this topic, this study also explored which methods were used to assess the outcomes of these efforts, how satisfied the dental hygiene directors were with their efforts, which challenges they perceived when covering this topic, and which changes they planned for the next three years.

In considering those findings, we became curious about how dental schools educate their students in the diagnosis of treatment needs and provision of care for patients with special health care needs. Our project was thus designed to conduct a study of U.S. and Canadian dental schools following the model 
used by Dehaitem et al. ${ }^{1}$ This replication in the dental school setting of Dehaitem et al.'s research had the objectives of exploring 1) which topics the dental programs covered; 2) how they educated their students about these topics and 3) assessed the outcomes of their efforts; 4) how satisfied they were with their curricular efforts; 5) which challenges they perceived; and 6) what changes they intended to implement in the future. In addition, this study focused specifically on how the schools approached the clinical education of their students in this area.

Concerning the reasons for this study, it seems important to reflect on the prevalence of disabilities among U.S. citizens and the need for oral health care services for these populations. The 2000 U.S. Census found that almost 50 million citizens have a long-term disability that challenges them on a daily basis. ${ }^{3} \mathrm{An}$ increased number of individuals with special needs might be partly due to the longer life expectancy of persons with disabilities due to improved health care. ${ }^{4}$ In 2000, the first U.S. surgeon general's report on oral health pointed out that persons with special health care needs suffer from both relatively poor oral health and problems accessing oral health care services. ${ }^{5}$ One of the many reasons for these access problems could have been that, over the past decades, a deinstitutionalization of patients with special needs has occurred, ${ }^{4,6}$ so that persons with developmental disabilities and other special needs have moved from large institutions to more community-based residences. While these patients lived in institutional settings, they may have had in-house medical and dental care, but that would have no longer been available to them when they moved into community living arrangements. ${ }^{4,7}$

Additionally, research has found that not all dentists feel prepared or have been willing to treat patients with various special needs. ${ }^{7,8}$ One possible reason for dentists' reluctance to provide care for these patients could be rooted in their dental education. For example, in 2002, Waldman and Perlman found that dentists reported a lack of knowledge about providing care for patients with special needs and a lack of clinical experiences concerning the treatment of these patients during dental school. ${ }^{7}$ In 2005, Dao et al. reported that the more education dentists had received about providing care for patients with special needs, the better their attitudes were and the more likely they were to actually provide services for these patients. ${ }^{8}$ While additional noneducational factors - such as concerns about adequate compensation and special arrangements needed when providing care for these patients - might also affect dentists' willingness to treat special needs patients, ${ }^{8,9}$ it seems nevertheless crucial to explore the role of dental education in this context. Given that large percentages of patients with mild or moderate challenges could be treated by general dentists, ${ }^{10}$ the question arises how dentists can be optimally prepared to provide this much-needed care.

Research has found that dentists who received classroom and clinic-based education in treating patients with special needs during their predoctoral dental training felt more comfortable caring for these patients and were thus more likely to provide this care. ${ }^{8}$ However, the majority of dentists in some earlier studies said they did not feel well prepared by their education. Cassamassimo et al. reported, for example, in 2004 that only one in four dentists had received education about special care dentistry. ${ }^{11}$ Consistent with the findings by Dao et al., ${ }^{8}$ these authors also found that the dentists who had not been exposed to these issues in lectures and clinical settings were less likely to treat patients with special health care needs. In addition, Wolff et al. found in 2004 that 50 percent of dental students reported they had not received any clinical training for the management of patients with mental retardation and that 75 percent said they had only little or no education or clinical training at all in the management of special needs patients. ${ }^{12}$

Given these findings, it is encouraging that the Commission on Dental Accreditation (CODA) of the American Dental Association (ADA) introduced Standard 2-24 in July 2004 to address this problem. This accreditation standard, which states that "Graduates must be competent in assessing the treatment needs of patients with special needs" (p. 28), ${ }^{2}$ required dental schools for the first time to ensure that curricular efforts are focused on educating their students about patients with developmental disabilities, complex medical problems, significant physical limitations, and other special needs. The question arises how dental schools have responded to this standard.

While Dehaitem et al. ${ }^{1}$ explored how dental hygiene programs reacted to meeting this standard, only one previous study focused on the situation in dental schools. Schwenk et al. ${ }^{13}$ collected data during the 2003-04 academic year from dental schools in the United States and Canada with a short fifteen-item survey. Given the timing of their survey, these data described the situation in North American dental schools around the time when the new CODA standard was being introduced. Schwenk et al. found 
that 40 percent of the responding schools had special care areas for the treatment of patients with special needs, and they described how schools without these special areas approached the question of how to care for these patients. While their findings emphasized the importance of recognizing the complex treatment needs of patients with special health care needs, they also found that less than 50 percent of dental schools required their students to have any clinical experiences with patients with special needs.

More recently, Kleinert et al. ${ }^{14}$ investigated how to incorporate learning about special needs patients into the dental school curriculum to meet the requirements of Standard 2-24. These authors developed a multimedia, virtual patient CD-ROM program that challenged students with case studies pertaining to care for patients with special care needs. They found that this method of teaching was effective in addressing the requirements outlined in the standard.

In consideration of the findings from previous research in dental schools ${ }^{13}$ and dental hygiene programs, ${ }^{1}$ our survey focused on defining the status quo in U.S. and Canadian dental schools after the new accreditation standard had been in effect for a number of years. In particular, our study analyzed how U.S. and Canadian dental schools are educating their students about special needs patients and, more specifically, which disabilities are being addressed in the predoctoral curriculum; it also sought to define which challenges and curricular changes can be anticipated in U.S. and Canadian dental schools concerning preparing their students to treat patients with special needs. Of particular interest was the question of how clinical education in these areas is unfolding, including whether schools have special clinics designed for patients with special treatment needs and, if so, how the treatment in such settings is structured.

\section{Methods}

This study was approved by the Institutional Review Board for the Health Sciences at the University of Michigan (IRB \# HUM00022288).

In July and August 2008, an e-mail was sent to the deans of the sixty-five dental schools in the United States and Canada, asking them to forward the web-based survey address to the person in their school most responsible for efforts concerning curriculum content about care for patients with special needs. No data were collected concerning who actu- ally responded to the survey. The e-mail addresses of the deans were obtained from various school and American Dental Education Association (ADEA) websites. Of the sixty-five deans who received the e-mail, twenty-two returned the surveys (response rate: 34 percent) by the end of October when the website was closed.

The investigators designed a draft of the survey based on the Dehaitem et al. ${ }^{1}$ survey. Questions concerning clinical services for the care of special needs patients were added, and the first draft was piloted with the students, staff, and faculty members of the Multicultural Affairs Committee at the University of Michigan School of Dentistry. Their feedback was used to revise the survey and develop the final version. The final version was uploaded onto UM Lessons, an online system operated by the university's Information Technology Division for collecting webbased survey data.

An introduction to the survey explained the purpose of the study, the length of the survey, and the fact that it was anonymous. The survey consisted of thirty-four questions. The first six (Part 1) asked for general information about the dental school programs. These questions inquired about the average number of graduates per year, which groups of special needs patients were seen at the school, in which year of dental education the students would see these patients and in what setting, and how the students were exposed to the topic of treating special needs patients during their dental education. Questions 7 to 15 (Part 2) inquired about the clinical setting in which these patients were treated, such as whether the schools had a dedicated clinic space for the treatment of patients with special needs. Questions 16 to 28 (Part 3) asked about the didactic and clinical experiences of the students concerning treating patients with special needs, the training of supervising faculty, and which teaching materials and assessments were used. The remaining questions (Part 4) asked respondents for their overall evaluations of their curricula and if they anticipated any changes in the next three years. If they expected any changes, they were asked to describe these changes. The last two questions asked the respondents to share the resources their school uses to educate students about patients with special needs and to provide feedback about the survey.

UM Lessons collects online survey data in the form of an Excel file. This file was imported into SPSS (Version 16.0). ${ }^{15}$ Descriptive statistics such as frequency distributions, means, and standard deviations were used to analyze the findings. 


\section{Results}

The survey was anonymous and did not allow separating the responses from U.S. dental schools from those from Canadian schools. Background information about the participating schools in general showed that the number of dental graduates per year in the twenty-two responding schools ranged from thirty-two to 176 students (Mean=74.2; SD=40.1).

Regarding how the U.S. and Canadian dental schools educate students about special needs patients, the data showed that all schools include material about special needs patients in their curricula. However, only fourteen of the twenty-two schools (64 percent) have a required course to cover this material. In response to the question about which types of special needs are covered, the majority of schools reported addressing Down syndrome, autism spectrum disorder, mental impairments, and age-related disabilities in their curricula (see Table 1). More than 80 percent of the responding programs said they cover the treatment of patients with motion impairments, cerebral palsy, and developmental delays, as well as patients with psychopathologies and hearing impairments. Seventeen of the twenty-two schools reported

\begin{tabular}{|c|c|c|}
\hline Patients with & Frequency & Percentage \\
\hline Down syndrome & 20 & $91 \%$ \\
\hline Autism spectrum disorder & 20 & $91 \%$ \\
\hline Mental impairments & 20 & $91 \%$ \\
\hline Age-related disabilities & 20 & $91 \%$ \\
\hline Developmental delays & 19 & $86 \%$ \\
\hline Psychopathology & 19 & $86 \%$ \\
\hline Motion impairments & 19 & $86 \%$ \\
\hline Cerebral palsy & 19 & $86 \%$ \\
\hline Hearing impairments & 18 & $82 \%$ \\
\hline Alzheimer's disease & 17 & $77 \%$ \\
\hline Addiction(s) & 16 & $73 \%$ \\
\hline $\begin{array}{l}\text { Attention deficit hyperactivity } \\
\text { disorder (ADHD) }\end{array}$ & 15 & $68 \%$ \\
\hline Closed head injuries & 11 & $50 \%$ \\
\hline Other & 8 & $36 \%$ \\
\hline \multicolumn{3}{|c|}{$\begin{array}{l}\text { Note: The wording of this question was as follows: "Accord- } \\
\text { ing to the new guidelines for accreditation, graduates of the } \\
\text { dental program must be competent in assessing the treatment } \\
\text { needs of patients with special needs. Which of the following } \\
\text { patients with special needs does your program address? Please } \\
\text { check all that apply." Note that respondents could select more } \\
\text { than one option. }\end{array}$} \\
\hline
\end{tabular}

Table 1. Frequencies and percentages of schools that educate their predoctoral dental students about patients with various special needs, by frequency of selection and percentage of total responding schools

Patients with addressing Alzheimer's disease, and sixteen schools include information about treating patients with addictions. Attention deficit hyperactivity disorder (ADHD) and closed head injuries were said to be covered less frequently.

Eight schools offered additional answers concerning other types of special needs that their programs address. Included in these responses were issues such as vision impairments (three schools) and medically compromised patients (two schools). Some physical and neurological impairments such as spina bifida, multiple sclerosis, and muscular dystrophy, spinal cord injuries, stroke, and genetic syndromes were named as well. One school mentioned addressing the issues of child abuse and neglect along with behavioral and sensory impairments in general, and one school said it addresses the issue of patients with seizure disorders.

Additional questions concerning how the schools educate their students about special needs patients addressed how they organize their curricula in this area. The majority of responding schools reported that their students begin learning about these issues in the third year of their dental program. Seven schools introduce their students to the topic in their first year, and five schools indicated that their students start this education in their second year. No school reported waiting until the fourth year of dental education to introduce their students to treating special needs patients.

In response to the question how the schools address this topic, 91 percent of the responding schools reported that they cover this topic in their clinical education, and 64 percent said they have a separate required course about special needs patients. Ten schools stated that their students receive information in occasional lectures in other courses or as part of another dental course (46 percent).

Table 2 provides an overview about the clinical settings in which dental schools reported that their students provide care for patients with special needs. All responding schools reported that their students treat special needs patients in the dental school clinics. However, 77 percent reported that students treat these patients in the general predoctoral clinics, while 36 percent said they have a special clinic designed for treating patients with special needs and 55 percent reported having their predoctoral students treat these patients in graduate clinics. Eighteen schools said they provide community-based/extramural clinic rotations for their students. In addition, ten schools said they have a hospital-based program where stu- 
dents gain clinical experiences with special needs patients. Three programs offered additional responses concerning where their students receive training, naming nursing facilities, chronic care hospitals, and other off-site locations.

Concerning how much time students spent on these issues during their clinical dental education, the responses ranged from two to 200 hours, with most students gaining between fifty and 100 hours of experience. Students at the twenty-two schools responding to our survey spend between zero and fifty hours in external clinics treating patients with special needs. In addition, time reportedly spent learning about this topic in the classroom ranged from eight to 148 hours, with an average of twenty-three hours of classroom-based material on these patients.

In order to best serve patients with special needs, appropriate behavior management and clinical techniques are needed. Concerning these techniques, 95 percent of the responding schools reported that their students learned the Tell-Show-Do technique as one type of behavior management approach. Most programs said they teach their students to use protective restraints ( 77 percent) and nitrous oxide (73 percent) when treating patients with special needs. In addition, 59 percent said they expose their students to the use of oral sedation and 36 percent teach intravenous sedation techniques. A smaller number of programs reported educating their students about general anesthesia for the treatment of patients with special needs ( 31 percent). One school reported teaching specific behavior management techniques.

The schools were also asked about who provides instruction concerning these efforts. Fifteen of the twenty-two schools reported that their supervising instructors had continuing education training in providing care for patients with special needs. Half of the schools reported that their faculty members were trained with either a master's degree or fellowship training in the care of patients with special needs. Another 50 percent reported employing instructors who were graduates of a general practice residency (GPR) program with an emphasis in care for patients with developmental disabilities. Some programs offered open-ended responses in which they reported having faculty members who had received training through a geriatric fellowship, practical clinical experiences, sedation residency training, graduate training, and specialty training. The dental qualifications of dentists said to be involved in these educational efforts included general dentists, dentists with training in the treatment of patients with special needs, pediatric and geriatric dentists, and oral and maxillofacial surgeons. Other types of instructors included behavioral scientists - e.g., psychologists or social workers - physicians, nurses, and teachers. Additional responses reported including a nutritionist, a dental hygienist, and a dental hygienist with a master's degree. In summary, these findings showed that instructors involved in these programs had quite varied experiences and backgrounds concerning the treatment of patients with special needs and that some schools took an interdisciplinary approach in these educational efforts.

In response to the question about which methods and resources the schools use in these educational efforts, nearly all programs reported that they use lectures and case studies to train their students about how to care for patients with special needs. In addition, 55 percent said they use small-group discussions, and 46 percent reported engaging their students in problem-based learning and demonstrations. Eight schools reported using videotapes or DVDs, and one school said it uses web-based, selfguided modules.

When the respondents were asked which resources the schools use, they provided open-ended responses such as references to different organizations and practitioners of varying levels of experience and specialty training. Other schools referred to specific textbooks, DVDs, pediatric dentistry-related curriculum material, online training, and Special Olympics as adjunct educational opportunities/resources for their students. One school reported having an interactive session with parents of children with special needs as part of its curricular efforts.

Table 2. Settings in which dental students gain experiences by treating patients with special needs, by frequency of selection and percentage of total responding schools

\begin{tabular}{lcc} 
Setting & Frequency & Percentage \\
\hline Dental school clinical setting & 22 & $100 \%$ \\
General predoctoral clinics & 17 & $77 \%$ \\
Special clinical area in the school & 8 & $36 \%$ \\
Graduate program dental clinics & 12 & $55 \%$ \\
Hospital-based setting & 10 & $46 \%$ \\
Community-based/external rotation & 18 & $82 \%$ \\
& & \\
Note: The wording of this question was as follows: "Select the \\
setting in which your students gain experiences by treating \\
patients with special needs. Please check all that apply." Note \\
that respondents could select more than one option.
\end{tabular}


Table 3 provides an overview of the specific topics covered in these educational efforts. Almost all schools said they teach their students about communication, patient management, behavior management, ethical issues, oral manifestations associated with disabilities, and giving instructions to parents and caregivers (each 96 percent). More than 90 percent of the responding schools said they also emphasize the prevention of oral disease for these patients and the use of fluorides as well as legal issues in their curricula (each 91 percent). Diet counseling was said to be included by nineteen of the twenty-two schools, and seventeen schools reported teaching their students about appointment scheduling, patient reception, and wheelchair transfers. Education about instrumentation and barrier-free environment issues was said to be included in 64 percent of the programs, and 55 percent reported teaching their students about tobacco cessation. One school indicated that it covers the subject of abuse in its curriculum.

The responses about how students' competence concerning the care of patients with special needs is

\section{Table 3. Types of patient-provider interactions ad- dressed when teaching about the treatment of patients with special needs, by frequency of selection and percentage of total responding schools}

\begin{tabular}{|c|c|c|}
\hline $\begin{array}{l}\text { Content of Educational Efforts } \\
\text { Regarding Patient Interaction }\end{array}$ & Frequency & Percentage \\
\hline Communication & 21 & $96 \%$ \\
\hline $\begin{array}{l}\text { Oral manifestations associated } \\
\text { with a disability }\end{array}$ & 21 & $96 \%$ \\
\hline $\begin{array}{l}\text { Instructions to parents and } \\
\text { caregivers }\end{array}$ & 21 & $96 \%$ \\
\hline Patient management & 21 & $96 \%$ \\
\hline Ethical issues & 21 & $96 \%$ \\
\hline Behavior management & 21 & $96 \%$ \\
\hline Prevention of oral diseases & 20 & $91 \%$ \\
\hline Fluorides & 20 & $91 \%$ \\
\hline Legal issues & 20 & $91 \%$ \\
\hline Diet counseling & 19 & $86 \%$ \\
\hline Patient reception & 17 & $77 \%$ \\
\hline Wheelchair transfer & 17 & $77 \%$ \\
\hline Appointment scheduling & 17 & $77 \%$ \\
\hline Barrier-free environment & 14 & $64 \%$ \\
\hline Instrumentation & 14 & $64 \%$ \\
\hline Tobacco cessation & 12 & $55 \%$ \\
\hline Other & 2 & $10 \%$ \\
\hline \multicolumn{3}{|c|}{$\begin{array}{l}\text { Note: The wording of this question was as follows: "Think } \\
\text { about the separate components of patient-provider interac- } \\
\text { tions. Which of these components are addressed in your teach } \\
\text { ing about the treatment of patients with special needs? Please } \\
\text { check all that apply." Note that respondents could select more } \\
\text { than one option. }\end{array}$} \\
\hline
\end{tabular}

assessed showed that 91 percent of the responding schools use written exams and 77 percent use clinical assessments. Only 18 percent said they use objective structured clinical exams (OSCEs), and only 9 percent reported using standardized patient scenarios when evaluating student performance. One school responded that it assesses its students based on their problem-based learning performance.

One additional objective of our study was to determine if dental schools have separate clinic areas specifically designed for the care of patients with special health care needs and, if so, how those clinics are set up. When asked where in the dental school patients with special needs are treated, eight of the twenty-two schools indicated that they have a special clinical area in their school that was designed for that purpose. These schools were asked to respond to additional questions about the set-up and financial support for those special clinic areas, which instructors work there, and how students are assigned to the clinics. The respondents reported that they have between three and twenty-two chairs in their specialty clinics. Six of the eight schools said they had modified the set-up of those clinics from the way they set up the general predoctoral clinics. One school reported having a special private operatory and waiting room specifically for patients with special needs as well as a partial wall to separate the clinic from the rest of the area. Another school reported having a separate front office staff person interact with the patients and specially trained dental assistants in that clinic. One school reported that its clinic has glassed-in operatories and papoose boards and nitrous oxide available for use with patients with special needs. Another school said it has several special needs clinics located throughout the state to facilitate access to care for patients with special needs and noted that each of these clinics is equipped with wheelchairs and stretchers. Another program said it had modified its clinic set-up to allow space for a caregiver to sit in the operatory with the patient, for the dental professional to access the patient chair from both sides, and to fit a wheelchair in the operatory. This same clinic was said to have a special "quiet" room with a wheelchair lift and enough space to turn a wheelchair around (five foot radius). Another school reported having a wheelchair lift/tilt gurney room.

A wide range of answers was provided about financial support for these specialty clinics. Half of the schools reported that the funding came partly from patient care revenue, including Medicaid. Other 
sources of funds were said to come from dental school funds, clinic operating funds, grants and government funds, state support, community dentistry funds, philanthropic efforts, and private grants.

The supervising dental educators in the specialty clinics were reported to have a variety of background experiences and training. The majority of the schools said they have dentists with experience in managing patients with special needs, with some experiences including GPR or advanced education in general dentistry (AEGD) training. Faculty members with other backgrounds were said to include oral medicine and orofacial pain specialists, oral surgeons, pediatric dentists, dental hygienists, and dentists with fellowships in geriatric dentistry, special training, master's degrees, or private practice experience. The support staff for the special clinics was said to range from one to twenty-three dental assistants and hygienists. One school reported it also has a patient care coordinator, and another said it has an appointment coordinator for its specialty clinic.

All but one of the eight schools reported that all students must rotate through this clinic on a mandatory basis; the remaining school responded that only certain students are selected to provide care in this clinic. The number of dental students being educated in these special clinical settings was said to range from one to eighteen students providing care at any one time. One of the programs indicated it has eight student practitioners and two additional student volunteers providing care at a given time. Another school reported dividing its dental class into teams of two for a total of nine teams. In these pairs, one student assists while the other student provides the treatment, and both students are assigned patients during a given clinical session. In addition, one school reported having seven students working in its special care clinic and four students in a nursing facility.

In addition to collecting information about how dental schools educate their students about patients with special needs, it was also important for our study to gain a better understanding of these educators' thoughts and experiences concerning their schools' educational efforts in this area. The respondents therefore answered questions asking them to indicate their satisfaction with the various aspects of their programs on a five-point scale ranging from $1=$ very dissatisfied to $5=$ very satisfied (see Table 4 for an overview). On average, the lowest satisfaction was reported concerning the teaching resources available (Mean=3.3). Over half of the schools were very dissatisfied, dissatisfied, or neutral concerning this issue. On the other hand, the majority of the schools were either satisfied or very satisfied with their programs' efforts in classroom-based settings (about 77 percent), with only three schools rating their satisfaction as low or very low and two schools as neutral. Satisfaction with each of the issues was comparable to the ratings of the classroom efforts. The average satisfaction with clinical experiences was 3.8; it was 3.7 with the patient pool, 3.6 with faculty expertise, and 3.5 with extramural experiences.

Table 5 provides an overview of respondents' ratings of various factors that might be barriers to educating their students about treating patients with special needs. Over 50 percent of the respondents perceived that curriculum overload is much or very much of a barrier. However, the majority of the respondents did not perceive that any other issue - such as a lack of educational resources, clinical sites, faculty expertise, or patients - created significant barriers.

Following up on the responses related to schools' satisfaction with their efforts and the barriers they perceived (see Tables 4 and 5), it was important to determine if the programs have any plans for change in their efforts to train their students to become competent providers for patients with special needs. The respondents were therefore asked if their programs plan to increase or decrease their students' time spent in the classroom, clinical, or extramural settings concerning providing care for patients with special needs. No school reported that it plans to decrease the time spent in any of the given areas. Four schools said they plan to increase their students' time in a classroom setting (18 percent), eight schools plan to increase the clinical time (36 percent), and six schools plan to increase extramural experiences (27 percent). Two programs responded to an openended question about which changes they anticipate in their programs. One school said it anticipates a full curriculum review prior to renovating a clinical area for patients with special needs, while another school said it plans to construct a separate clinical area for educating its students about the treatment of these patients.

\section{Discussion}

The amendment to the accreditation standards in $2004^{2}$ emphasized that dental schools should prepare their predoctoral students to provide care for patients with special needs by requiring them to educate students about diagnosing the treatment 
Table 4. Respondents' satisfaction with various aspects of their programs' educational efforts concerning the treatment of patients with special needs, by percentage of total responding schools

\begin{tabular}{lcccccc} 
& 1=very dissatisfied & 2=dissatisfied & 3=neither/nor & 4=satisfied & 5=very satisfied & Mean (SD) \\
\hline Teaching resources & $5 \%$ & $5 \%$ & $55 \%$ & $23 \%$ & $9 \%$ & $3.3(.9)$ \\
Extramural experiences & $5 \%$ & $9 \%$ & $32 \%$ & $41 \%$ & $14 \%$ & $3.5(1.0)$ \\
Faculty expertise & $5 \%$ & $14 \%$ & $14 \%$ & $50 \%$ & $18 \%$ & $3.6(1.1)$ \\
Patient pool & $5 \%$ & $5 \%$ & $36 \%$ & $27 \%$ & $27 \%$ & $3.7(1.1)$ \\
Clinical experiences & $5 \%$ & 0 & $27 \%$ & $50 \%$ & $18 \%$ & $3.8(0.9)$ \\
Classroom experiences & $5 \%$ & $9 \%$ & $9 \%$ & $55 \%$ & $23 \%$ & $3.8(1.1)$
\end{tabular}

Note: Percentages may not total $100 \%$ because of rounding.

Table 5. Perceived level of importance of barriers to educating dental students about the treatment of patients with special needs, by percentage of total responding schools

\begin{tabular}{lcccccc} 
& 1-not at all & 2 & 3 & 4 & $5=$ very much & Mean (SD) \\
\hline Lack of patients & $32 \%$ & $32 \%$ & $23 \%$ & $9 \%$ & $5 \%$ & $2.2(1.2)$ \\
Lack of faculty expertise & $36 \%$ & $14 \%$ & $32 \%$ & $9 \%$ & $5 \%$ & $2.3(1.2)$ \\
Lack of clinical sites & $41 \%$ & $14 \%$ & $9 \%$ & $27 \%$ & $9 \%$ & $2.5(1.5)$ \\
Lack of educational resources & $23 \%$ & $18 \%$ & $27 \%$ & $27 \%$ & $5 \%$ & $2.7(1.2)$ \\
Curriculum already overloaded & $18 \%$ & $9 \%$ & $18 \%$ & $50 \%$ & $5 \%$ & $3.1(1.2)$
\end{tabular}

Note: Percentages may not total $100 \%$ because of rounding.

needs of these patients. The objective of this study was to analyze how dental schools in the United States and Canada had responded to this challenge by the beginning of the 2008-09 academic year. The fact that only twenty-two of the sixty-five U.S. and Canadian dental schools that received a request for information responded to this survey could be interpreted as a low level of interest in this topic by nearly two-thirds of the schools. However, another reason for this low response rate could be that the schools might be less likely to respond to a web-based survey compared to a survey they receive in the mail. ${ }^{1,16,17}$ For example, when Schwenk et al. mailed a survey to U.S. and Canadian dental schools in 2007, they had a 64 percent response rate compared to the 34 percent response rate of our study. ${ }^{13}$ Future research with dental schools should consider providing paper copies and stamped return envelopes to collect survey data together with a web-link, because the low response rate to our web-based survey clearly limits the value of our findings.

A second limitation is the fact that the survey was anonymous. The anonymity does not allow the analysis of U.S. responses separately from the Canadian responses. This is an important issue because this accreditation standard was introduced only in the United States.
Given these two challenges, the responses of the twenty-two dental schools should be seen as a first exploratory step towards identifying potential barriers; it could also be useful in providing other schools with ideas concerning best practices and ways to improve their educational efforts in this area. In short, the findings will hopefully provide dental programs with a range of ideas about how to structure their education about patients with special health care needs.

In particular, the findings highlight the following key issues: which special needs are addressed by these predoctoral dental programs and how the schools address them; where the schools train their students clinically in the treatment of patients with special needs; which topics they cover in educating students about these patients; how satisfied the respondents are with aspects of their schools' educational efforts in this area; and which factors are perceived as barriers to educational efforts.

\section{Special Needs Addressed}

On the positive side, all responding schools reported that they educate their students about the treatment of patients with special needs. However, only 63 percent of these schools said they have a required course on this topic, and ten schools re- 
ported that their students receive this education in occasional lectures only. When the respondents were asked which types of special needs issues they cover, it became evident that the schools cover a broad range in the issues they address. For example, only 73 percent of the programs said they prepare their students to provide care for patients with addictions. Given that alcoholism and drug addiction are quite prevalent in the United States, can have detrimental effects on oral health, and can lead to challenges during treatment, it would be quite beneficial to prepare all future dentists about these issues. In addition, only 86 percent of the responding schools said they teach their students about patients with developmental delays despite the fact that this type of special need is specifically mentioned in the new accreditation standard. ${ }^{2}$ Another interesting finding was that only 91 percent of responding schools said they teach their students about age-related disabilities and even fewer schools (77 percent) about Alzheimer's disease. It would have been helpful to inquire about the schools' educational efforts concerning pediatric versus adult patients with special needs because Dao et al. ${ }^{8}$ found a difference in the professional behavior of general dentists depending on the age of their patients with given special health care needs. Future research should address this issue.

Concerning the timing of educational efforts in this context, it is interesting to reflect on the fact that 41 percent of responding schools reported that their students are introduced to the topic of treatment for patients with special needs in the third year of the curriculum and 27 percent reported that their students are introduced to these issues in their second year. One might reflect on the consequences of not introducing students earlier to these issues and the lack of educational experiences these students might face. Introducing this topic from the beginning of the students' dental education might be considered a best practice for shaping professional attitudes and preparing predoctoral students to provide quality treatment to patients with special needs.

In addition, it is quite remarkable that the schools reported that their students spend between two and 200 hours in a clinical setting and between eight and 148 hours in classroom-based education on the topic of patients with special needs. One might question whether future dental care providers can develop the competencies needed to diagnose the treatment needs of patients with special needs as required by the new standard or provide any care for patients with special needs if they spend only two hours in a clinical setting and/or eight hours in a classroom setting on these topics.

Despite the fact that the recruitment of qualified clinical faculty trained in the care of patients with special needs can be a challenge, this study found that some schools are exemplary in this regard. These schools reported putting together interdisciplinary teams of providers including a nutritionist and trained dental assistants and hygienists to work with dental faculty members and students in the care of special needs patients. Educating dental students about an interdisciplinary approach to dental care in general can be regarded as a best practice that follows the recommendations of the U.S. surgeon general ${ }^{5}$ and the Institute of Medicine report on the future of dental education. $^{18}$

\section{Special Clinic Areas for Treating Special Needs Patients}

Dehaitem et al. reported in 2008 that only 42 percent of U.S. dental hygiene programs provided their students with clinical experiences in the care for patients with special needs. ${ }^{1}$ It is therefore encouraging that 100 percent of the twenty-two dental schools that responded to our survey reported that their students gain experience in treating patients with special needs in clinical settings. Eight schools reported having a designated clinical area for dental care of patients with special health care needs. Data from these eight schools showed that these special clinical areas are designed to provide more space to allow providers to access patients from both sides of the dental chair, have room for wheelchairs, and extra space for a caregiver to be present during treatment. In addition, the students educated in these clinics were said to have the support of well-trained staff and faculty members. These best practices are admirable because they undoubtedly offer excellent opportunities for dental students to be educated about the treatment of patients with special health care needs. However, one might reflect on the potential challenge of convincing future dental care providers to treat patients with special health care needs in general dental practices if they see that these patients are treated only in special clinical areas in their dental school. It seems crucial for dental educators to recognize the tension between the objective of teaching students clinically in the best possible way and the objective of decreasing students' apprehension about providing care for these patients in general practices. 
A logical follow-up question in this context should be to explore how well predoctoral dental students can be prepared clinically to treat patients with special needs if their training takes place in standard dental school clinics. Putting serious thought into how to develop the best possible clinical training opportunities in this context includes considerations about funding for a specialized clinical setting. The data from our study show that schools use various funding models to support their efforts in this area. Future research is needed to develop recommendations concerning the best way to educate future dental care providers clinically for treating patients with special health care needs. In addition, given that ten schools in our study reported that their students receive their clinical training concerning these patients in a hospital setting, it seems crucial to reflect on how to adequately educate students about which patients with special needs should be treated in a hospital setting and which patients they can accept into their own private practices.

\section{Topics Covered and Satisfaction with Educational Efforts}

Our study found that nearly all responding schools teach their students about behavior management, patient management, and communication with special needs patients including giving instructions to caregivers and patients. In addition, most schools teach their students about oral manifestations associated with a disability and ethical issues pertaining to care of such patients. However, fewer programs were said to focus on oral disease prevention regarding these patients and practice management concerns such as legal issues and scheduling of appointments at times when patients are most cooperative. Future research should develop clearer guidelines and resource materials concerning these issues.

The results concerning respondents' satisfaction with their educational efforts showed that the programs differ widely in their degree of satisfaction. The lowest average satisfaction was reported concerning available teaching resources. This response suggests that future efforts should focus on creating better resource materials such as textbooks, videos, and clinical manuals to support curricular efforts in this context. Not surprisingly, this lack of educational resources was also rated as the second greatest perceived barrier, following curriculum overload.

\section{Conclusions}

The results of our study lead us to the following recommendations and conclusions:

1. This study found a wide range of approaches to educating predoctoral dental students about treating patients with special health care needs. In order to eliminate oral health disparities and access to care issues for these patients, future research should focus on developing best practices for dental school efforts in this context.

2. Given the new accreditation standard concerning special needs patients, clinical education efforts have to be revisited. In particular, it is noteworthy that eight of the twenty-two responding schools have special clinic areas designated for the treatment of patients with special health care needs. These exemplary efforts could be analyzed to determine best practices for educating future health care providers about treating special needs patients.

3. Future research should focus on determining how U.S. dental schools overall are responding to the new accreditation standard and especially if the narrow focus of this standard on diagnosing the treatment needs of special needs patients achieves the goal of preparing future providers to be confident and willing to accept these patients in their practices. Expanding the standard to include being competent to provide basic care for this patient population should be considered.

\section{REFERENCES}

1. Dehaitem MJ, Ridley K, Kerschbaum WE, Inglehart MR. Dental hygiene education about patients with special needs: a survey of U.S. programs. J Dent Educ 2008;72(9): 1010-19.

2. Commission on Dental Accreditation. Accreditation standards for dental education programs. Chicago: American Dental Association, 2010.

3. U.S. Census Bureau. Census 2000 brief. Disability status: 2000, March 2003. At: www.census.gov/prod/2003pubs/ c2kbr-17.pdf. Accessed: November 29, 2008.

4. Fenton SJ, Hood H, Holder M, May PB Jr, Mouradian WE. The American Academy of Developmental Medicine and Dentistry: eliminating health disparities for individuals with mental retardation and other developmental disabilities. J Dent Educ 2003;67(12):1337-44.

5. Oral health in America: a report of the surgeon general. Rockville, MD: U.S. Department of Health and Human Services, National Institute of Dental and Craniofacial Research, National Institutes of Health, 2000.

6. Waldman HB, Fenton SJ, Perlman SP, Cinotti DA. Preparing dental graduates to provide care to individuals with special needs. J Dent Educ 2005;69(2):249-54. 
7. Waldman HB, Perlman SP. Preparing to meet the dental needs of individuals with disabilities. J Dent Educ 2002; 66(1):82-5.

8. Dao LP, Zwetchkenbaum S, Inglehart MR. General dentists and special needs patients: does dental education matter? J Dent Educ 2005;69(10):1107-15.

9. Waldman HB, Perlman SP. Mandating education of dental graduates to provide care to individuals with intellectual and developmental disabilities. Ment Retard 2006;44(3):184-8.

10. Steinberg BJ. Issues and challenges in special care dentistry. J Dent Educ 2005;69(3):323-4.

11. Cassamassimo PS, Seale NS, Ruehs K. General dentists' perceptions of educational and treatment issues affecting access to care for children with special health care needs. J Dent Educ 2004;68(1):23-8.

12. WolffAJ, Waldman HB, Milano M, Perlman SP. Dental students' experiences with and attitudes toward people with mental retardation. J Am Dent Assoc 2004;135(3):353-7.
13. Schwenk DM, Stoeckel DC, Rieken SE. Survey of special patient care programs at U.S. and Canadian dental schools. J Dent Educ 2007;71(9):1153-9.

14. Kleinert HL, Sanders C, Mink J, Nash D, Johnson J, Boyd S, Challman S. Improving student dentist competencies and perception of difficulty in delivering care to children with developmental disabilities using a virtual patient module. J Dent Educ 2007;71(2):279-86.

15. SPSS Inc. SPSS 16.0 Student Version for Windows (SA). New York: Prentice Hall, 2008.

16. Leece P, Bhandari M, Sprague S, Swiontkowski MF, Schemitsch EH, Tornetta P, et al. Internet versus mailed questionnaires: a controlled comparison (2). J Med Internet Res 2004;6:e39.

17. Couper MP, Blair J, Triplett T. A comparison of mail and email for a survey of employees in U.S. statistical agencies. J Official Stats 1999;15:390-6.

18. Field MJ, ed. Dental education at the crossroads: challenges and change. An Institute of Medicine Report. Washington, DC: National Academy Press, 1995. 